\title{
Emergency Surgery for Acute Dissection of the Ascending Aorta
}

\author{
Kambiz Alizadeh, ${ }^{1}$ Masoomeh Tabari, ${ }^{2,}$ Zohreh Mohammadzadeh Tabrizi, ${ }^{3}$ and Azra Izanloo ${ }^{4}$ \\ ${ }^{1}$ Assistant Professor of Cardiac Surgery, Faculty of Medicine, Mashhad University of Medical Sciences, Mashhad, Iran \\ ${ }^{2}$ Associate Professor of Anaesthesiology, Faculty of Medicine, Mashhad University of Medical Sciences, Mashhad, Iran \\ ${ }^{3}$ Master of ICU, Mashhad University of Medical Sciences, Mashhad, Iran \\ ${ }^{4}$ Master in Medical Education, Mashhad University of Medical Sciences, Mashhad, Iran \\ "Corresponding author: Masoomeh Tabari, Faculty of Medicine, Mashhad University of Medical Sciences, Mashhad, Iran. Tel/Fax: +98-5138417402, E-mail: tabarim@mums.ac.ir
}

Received 2016 August 27; Accepted 2016 December 24.

\begin{abstract}
Background: Aortic dissection is a nonprevalent disease and its late diagnosis can be life-threatening with a high mortality rate. The timely treatment of this disease can increase the survival rate considerably.

Objectives: The aim of this study was to provide a surgery report of patients with aortic dissection operated in a community hospital.

Methods: In this descriptive study, the mortality rate and operation events of five patients with an acute aortic dissection referred to a community hospital were reported during the period of 2011 to 2015.

Results: In this study, 5 patients with aortic dissection referred to the cardiology emergency ward of the hospital were operated. Two of five patients were males; one of them had the Marfan's disease and another one had the bicuspid aortic valve. The remainders were females; the first case was an old woman with a traumatic chest injury who died during the operation due to arrhythmia. The second case was a 42-year-old pregnant woman suspicious to Marfan's disease with a history of sudden death in her brother. The third woman was a case of aneurysm of ascending aorta with a bicuspid aortic valve.

Conclusions: The findings of this study show that early diagnosis and timely operation can increase the survival rate of patients with an aortic dissection.
\end{abstract}

Keywords: Aortic Dissection, Cardiac Surgery, Mortality

\section{Introduction}

Despite the fact that the aortic dissection is a nonprevalent disease, its late diagnosis can be life-threatening with a high mortality rate $(1,2)$. It has been shown that the mortality rate is increased by one percent for each hour delay in the treatment. However, early diagnosis and timely treatment of the disease can significantly increase the survival rate of the patients (3-5). In some studies, a mortality rate of $80 \%$ has been reported for an untreated aorta dissection $(6,7)$.

Considering that the acute aortic dissection surgery which has been performed as soon as possible after diagnosing can decrease the mortality and morbidity rates, this study was conducted to describe our experiences with five cases of the acute aortic dissection surgery.

\section{Methods}

This descriptive study was performed on five patients with the acute aortic dissection referred to a general hospital during the period of 2011 to 2015 . In this study, the medical records of patients undergoing aortic dissection surgery were examined retrospectively.
Before entering into the operating room, at least one imaging study was performed on all patients (TEE or CTangiography or both of them).

In the operating room after standard monitoring, two large bore IV and two arterial line were inserted. After preoxygenation, anesthesia was induced with etomidate, fentanyl and midazolam, and cisatracurium was also used as a muscle relaxant. After intubation, a central venous catheter was inserted into a right internal jugular vein. After median sternotomy and the IV injection of heparin (3 $\mathrm{mg} / \mathrm{kg}$ ), an aortic cannula was inserted into the proximal of aortic arch and venous cannula was placed into the right atrium, cardiopulmonary bypass was started. The cooling of the body of the patients during the surgical procedure was continued to $30^{\circ} \mathrm{C}$. Then, the heart was fibrillated with ice chips. After opening the aorta (both true and false lumen) cardioplegia was infused directly into the coronary ostium. An aortic valve was repaired in three cases. Aortic root replacement (the Bentall procedure) was performed in one case, and supracoronary aortic replacement was performed for the last case. Meticulous hemostasis was performed for all patients. The patients were transferred to the intensive care unit (ICU) with the endotracheal tube.

The mortality rate of these patients, the length of stay 
in the hospital and ICU, comorbidity and the underlying and hemodynamic parameters of the patients were extracted. After coding these parameters, they were subjected to descriptive analysis and the McNamara test to investigate the changes in the process of laboratory factors of the patients before and after the operation.

\section{Results}

Patients with a mean age of $58.2 \pm 19.89$ years (40\% male) were enrolled in the study. The mean length of stay for patients was 5 days in the ICU and $4 \pm 1.41$ days in the cardiac surgery ward. Demographic data are presented in Table 1.

Four patients were alive and they had no problem after a two-year follow-up, only one patient died in the operation room due to refractory arrhythmia. Among these five patients, three had simultaneous aortic valve repair; the Bentall procedure was performed for one patient, and the last case had supra coronary ascending aorta replacement.

The results of the McNamara test showed no significant difference between the patients' tests (PLT, PT, PTT, NA, $\mathrm{K}, \mathrm{BS}, \mathrm{BUN}, \mathrm{CR}$, PH, PACO2, PAO2, HCO3, BE, LACTAT, GLU) before and after the surgery $(\mathrm{P}=0.05)$. However, there was only a significant difference in the mean hematocrit (HCT) level before and after the surgery $(\mathrm{P}=0.027)$.

\section{Discussion and Conclusion}

Aortic dissection is especially prevalent in the sixth and seventh decades of one's life (60 - 70 years old) and its prevalence rate in men is twice as high as that of women (8). The present study showed a mean age of 58 years for these patients, which is consistent with the results of previous studies. It has been shown that the predisposing factors of aortic dissection in terms of its importance and prevalence are hypertension, an aortic valve disease, pregnancy, cocaine abuse, chest trauma and a history of open heart surgery $(9,10)$. In this study, the results showed a history of hypertension, pregnancy and the bicuspid aortic valve in the patients, which can be considered as risk factors.

In a study in the United States, the results suggested that $90 \%$ of patients had chest pain and $17 \%$ had neurologic symptoms $(2,10)$. In this regard, the aforementioned study revealed that more than $40 \%$ of the patients had chest pain. This statistical difference could be explained in terms of the limited sample size of our study.

It is important that the blood pressure variation be considered during the period of induction of anesthesia, intubation time and aortic cross-clamping. Moreover, during the operation, availability of blood products is critical due to potential blood losing. As pointed out, for patients undergoing aortic dissection, it is important to monitor systemic blood pressure, neurologic function and intravascular volume. Totally, it is recommended to plan the pharmacologic interventions and hemodynamic management strategies which could potentially control the hypertension (11).

In total, aortic dissection is a fatal disease but the rate of mortality can be reduced by early diagnosis and timely treatment, and thereby the prognosis will be improved remarkably in the patients.

The present study was conducted to examine the efficacy of early diagnosis and timely operation of the patients with the aortic dissection. Four of our patients (80\%) were alive after the operation and discharged from the hospital without any problem. Hence, early diagnosis and timely treatment of the disease in these patients can improve the prognosis.

\section{References}

1. Thorsgard ME, Morrissette GJ, Sun B, Eales F, Kshettry V, Flavin $\mathrm{T}$, et al. Impact of intraoperative transesophageal echocardiography on acute type-A aortic dissection. J Cardiothorac Vasc Anesth. 2014;28(5):1203-7. doi: 10.1053/j.jvca.2014.05.012. [PubMed: 25281039].

2. Mann DL, Zipes DP, Libby P, Bonow RO. Braunwald's heart disease: a textbook of cardiovascular medicine. Elsevier Health Sciences; 2014.

3. Khan IA, Nair CK. Clinical, diagnostic, and management perspectives of aortic dissection. Chest. 2002;122(1):311-28. [PubMed: 12114376].

4. Harris KM, Strauss CE, Duval S, Unger BT, Kroshus TJ, Inampudi S, et al. Multidisciplinary standardized care for acute aortic dissection: design and initial outcomes of a regional care model. Circ Cardiovasc Qual Outcomes. 2010;3(4):424-30. doi: 10.1161/CIRCOUTCOMES.109.920140. [PubMed: 20647576].

5. Chnstoph A, Kim A. New frontiers in diagnostic and management of aortic dissection. Circulation. 2003;108:220-36.

6. Hagan PG, Nienaber CA, Isselbacher EM, Bruckman D, Karavite DJ, Russman PL, et al. The International Registry of Acute Aortic Dissection (IRAD): new insights into an old disease. JAMA. 2000;283(7):897903.

7. Hurt A, Michael Smith J, Engel AM. Predictors and outcomes associated with intraoperative aortic dissection in cardiac surgery.J Cardiac Surg. 2008;23(5):422-5.

8. Oskoui R, Lindsay JJ. Aortic dissection in women $<40$ years of age and the unimportance of pregnancy. Am J Cardiol. 1994;73(11):821-3. [PubMed: 8160623].

9. Bonser RS, Ranasinghe AM, Loubani M, Evans JD, Thalji NM, Bachet JE, et al. Evidence, lack of evidence, controversy, and debate in the provision and performance of the surgery of acute type A aortic dissection. J Am Coll Cardiol. 2011;58(24):2455-74. doi: 10.1016/j.jacc.2011.06.067. [PubMed: 22133845].

10. Cohn LH. Cardiac surgery in the adult. ; 2003.

11. Hines RL, Marschall K. Stoelting's anesthesia and co-existing disease. Elsevier Health Sciences; 2012. 
Table 1. Demographic Characteristics of the Patients

\begin{tabular}{|c|c|c|c|c|c|c|c|c|c|c|}
\hline Patient Number & Sex & Age, $y$ & Chest Pain & hypertension & $\begin{array}{l}\text { Diabetes Mellitus and } \\
\text { Back Pain }\end{array}$ & $\begin{array}{l}\text { Previous Aortic Valve } \\
\text { Disease }\end{array}$ & History Cardiac Surgery & $\begin{array}{l}\text { Blood Transfusion in } \\
\text { Operate Room }\end{array}$ & Follow-Up & EF \\
\hline 1 & F & 37 & + & . & . & + & . & + & Live & 45 \\
\hline 2 & $\mathrm{~F}$ & 73 & + & + & - & + & . & + & Death & 50 \\
\hline 3 & $\mathrm{~F}$ & 70 & - & + & - & + & - & + & Live & 45 \\
\hline 4 & M & 75 & . & . & . & + & . & . & Live & 60 \\
\hline 5 & M & 36 & . & . & + & . & . & + & Live & 55 \\
\hline
\end{tabular}

